\title{
Limitações químicas ao crescimento inicial de Eucalyptus saligna em solos arenosos do Pampa Gaúcho: estudo de caso
}

\author{
Chemical constraints to initial growth of Eucalyptus saligna in sandy soils of \\ Pampa Gaúcho: a case study
}

Claudiney do Couto Guimarães ${ }^{\mathrm{I}}$ Eduardo Pagel Floriano ${ }^{\mathrm{II}}$ Frederico Costa Beber Vieira ${ }^{\mathrm{II}}$

\section{RESUMO}

O trabalho objetivou identificar os principais atributos químicos de solo que limitam o crescimento do Eucalyptus saligna em plantios sem calagem na região Sudoeste do Rio Grande do Sul, bem como determinar os valores críticos de cada fator. $O$ estudo foi realizado em povoamentos florestais de dois Latossolos Vermelhos e um Neossolo Quartzarênico da região. Foram realizadas análises químicas do solo $e$, através de correlações $(P<0,05)$ entre estes e variáveis de crescimento das plantas, verificou-se que os atributos que mais limitaram o crescimento das plantas foram a saturação por Al, a saturação por bases e o teor de Mg trocável, com decréscimo de até 50\% nos parâmetros de crescimento. As correlações com os atributos químicos da camada subsuperficial de solo (20-40cm) foram mais significativas do que na camada superficial $(0-20 \mathrm{~cm})$. Os niveis críticos médios para obtenção de $80 \%$ do rendimento relativo no crescimento em diametro e em volume de plantas foram de $79 \%$ para saturação por Al, 8,3\% para saturação por bases e 0,3 cmol $\mathrm{dm}^{-3}$ para o teor de $\mathrm{Mg}$ trocável. Os resultados indicam que a calagem não deve ser suprimida dos plantios de eucalipto em solos ácidos do Pampa Gaúcho, mas a quantidade necessária de calagem para esta cultura parece ser menor do que a atualmente recomendada.

Palavras-chave: nível crítico de acidez, calagem, correlação, eucaliptocultura.

\section{ABSTRACT}

The study aimed to identify the main soil chemical attributes that constrains the Eucalyptus saligna growth in nolimed plantations at the southwestern region of Rio Grande do Sul state, as well as to determine the threshold values of each attribute. Forest plantations from two Oxisols and one Quartzipsamment were evaluated. Correlation analysis $(P<0.05)$ between soil chemical attributes and plant growth variables indicated that the most constraining soil attributes were the Al saturation, bases saturation and exchangeable Mg content, whose decrease in plant growth was up to 50\%. Subsurface soil attributes (20-40cm depth) had closer relation with plant growth than surface soil ones (0$20 \mathrm{~cm}$ ). The average threshold values for achieving $80 \%$ of the relative yield capacity in diameter growth of trunks and in volume were $79 \%$ for Al saturation, $8.3 \%$ for bases saturation and 0.3 cmol $\mathrm{dm}^{-3}$ for exchangeable $\mathrm{Mg}$. The results evidenced that liming should not be suppressed in eucalypt plantations on acid soils at south Brazilian Pampa and that the required amount of lime seem to be smaller than that currently recommended.

Key words: threshold value of soil acidity, liming, correlation, eucalyptus cultivation.

\section{INTRODUÇÃO}

A silvicultura Brasileira, especialmente com o gênero Eucalyptus, vem se destacando em nível mundial, principalmente pela alta produtividade e pela competitividade dos custos de produção. Em 2012, o Brasil contabilizou 6,66 milhões de hectares com florestas plantadas com pinus e eucalipto, sendo que 5,10 milhões correspondem às áreas cultivadas com eucalipto (ABRAF, 2013). Para o estado do Rio Grande do Sul (RS), a área cultivada em 2012 foi de 284 mil hectares com eucalipto e 165 mil hectares com pinus, colocando o estado como o sexto maior produtor de madeira oriunda de florestas plantadas no país. A área com cultivo de eucalipto no estado do RS aumentou em cerca de 50\% nos últimos cinco anos (ABRAF, 2013) e há potencial para aumentos expressivos.

IPrograma de Pós-graduação em Engenharia Florestal, Universidade Federal de Santa Maria (UFSM), Santa Maria, RS, Brasil.

II Universidade Federal do Pampa (Unipampa), Campus São Gabriel, Av. Antonio Trilha, 1847, 97300-000, São Gabriel, RS, Brasil. E-mail: fredericovieira@unipampa.edu.br. "Autor para correspondência. 
Os solos utilizados para a cultura de eucalipto no Brasil geralmente são ácidos e pobres em matéria orgânica e nutrientes (VALE et al., 1996; GONÇALVES, 2002) e, no RS, não é diferente. As espécies do gênero Eucalyptus apresentam, em geral, maior tolerância a valores elevados de atividade de $\mathrm{Al}^{+3}$ na solução do solo do que a maioria das culturas agrícolas (SILVA et al., 2004; POSCHENRIEDER et al., 2008; TAHARA et al., 2008), além de requererem níveis de $\mathrm{Ca}$ e $\mathrm{Mg}$ inferiores aos estabelecidos como críticos para a maioria das culturas (BARROS \& NOVAIS, 1990; RIBEIRO et al., 1999). Isso favoreceu para que grande parte dos plantios dessa espécie fosse realizada sem calagem. Entretanto, para obter maiores produtividades e garantir a sustentabilidade nutricional, é necessário realizar calagem e fertilização ajustadas para cada área de plantio (GONÇALVES \& BENEDETTI, 2004).

Nos estados do Rio Grande do Sul e Santa Catarina, a calagem e a fertilização das culturas são realizadas com base na recomendação oficial elaborada pela Comissão de Química e Fertilidade do Solo desses dois estados (COMISSÃO, 2004). Porém, particularidades de plantios relacionadas ao tempo e espaço podem fazer com que os níveis críticos para a tomada de decisão da calagem e para a recomendação de fertilizante de culturas anuais não sejam adequados para plantios florestais (BARROS et al., 2004). Além disso, a evolução dos sistemas de produção florestal, principalmente do ponto de vista genético, com materiais de rápido crescimento e maior resposta a práticas de manejo, e a expansão do cultivo para áreas com solos menos férteis, fazem com que a acurácia do sistema de recomendação para os atuais plantios de eucalipto em solos do Pampa seja questionável. Apesar da expansão da eucaliptocultura no Sul do Brasil, poucos estudos têm buscado aprimorar o atual sistema de recomendação de adubação e calagem para cultivos dessa espécie na região. Essa lacuna é ainda mais grave em solos de textura arenosa das regiões da Campanha e Fronteira Oeste do RS, onde a expansão do cultivo de eucalipto tem sido significativa e recente.

Nesse contexto, este trabalho teve por objetivo identificar os principais atributos químicos do solo que limitam o crescimento de Eucalyptus saligna em plantios sem calagem em solos arenosos representativos do Pampa gaúcho, bem como determinar os valores críticos dos principais fatores limitantes.

\section{MATERIAL E MÉTODOS}

O presente estudo foi realizado em dois povoamentos florestais localizados nos municípios de Unistalda e São Francisco de Assis, pertencentes à Stora Enso Florestal RS, com coordenadas 29 $04^{\prime}$ $\mathrm{S}$ e $55^{\circ} 15^{\prime} \mathrm{W}$ e $29^{\circ} 23^{\prime} \mathrm{S}$ e $55^{\circ} 11^{\prime} \mathrm{W}$, respectivamente. O clima da região caracteriza-se como sendo do tipo $\mathrm{Cfa}$, de acordo com a classificação de Koppen. Os solos dos locais avaliados são classificados como Latossolo Vermelho Distrófico (LVd3), Latossolo Vermelho Distrófico típico textura média arenosa (LVd4) e Neossolo Quartzarênico Órtico típico textura areia franca (RQo1) (EMBRAPA, 2006).

Para a implantação dos povoamentos florestais, realizou-se a subsolagem em junho de 2007 , utilizando subsolador com três hastes, incorporando $300 \mathrm{~kg} \mathrm{ha}^{-1}$ de fosfato natural reativo (GAFSA, 12\% $\mathrm{P}_{2} \mathrm{O}_{5}$ solúvel em ácido cítrico) no centro e a $40 \mathrm{~cm}$ de profundidade, seguido de gradagem leve. O plantio, realizado em julho de 2007, utilizou mudas clonais de Eucalyptus saligna no espaçamento 3,5x2,5m, totalizando uma densidade inicial de 1150 plantas $\mathrm{ha}^{-1}$. Foram realizadas três fertilizações pós-plantio, sendo a primeira 15 dias após o plantio, utilizando a fórmula $\mathrm{N}-\mathrm{P}_{2} \mathrm{O}_{5}-\mathrm{K}_{2} \mathrm{O}$ de 06-30-06 + 0,6\% Bo, $110 \mathrm{~g}$ planta $^{-1}\left(126,5 \mathrm{~kg} \mathrm{ha}^{-1}\right)$, dividida em duas subdoses de $55 \mathrm{~g}$, incorporadas a $15 \mathrm{~cm}$ de cada lado da muda. A segunda adubação foi realizada aos 90 dias pós-plantio, utilizando a fórmula 20$05-20+0,2 \%$ Bo $+0,4 \%$ Zn, 122 g planta $^{-1}(140 \mathrm{~kg}$ $\left.\mathrm{ha}^{-1}\right)$, aplicada manualmente na projeção da copa. A terceira, aos 270 dias, utilizou a fórmula 22-00$18+1 \% \mathrm{~S}+0,3 \%$ B, $122 \mathrm{~g} \mathrm{planta}^{-1}\left(140 \mathrm{~kg} \mathrm{ha}^{-1}\right)$, aplicada mecanicamente na entrelinha. Em nenhum momento foi realizada calagem.

As variáveis de crescimento de planta foram determinadas utilizando os dados de inventário florestal fornecidos pela Empresa, que foi realizado em outubro de 2009 (aproximadamente 28 meses após o plantio). Para o presente estudo, utilizaramse os dados de 18 unidades experimentais (cinco, seis e sete unidades para os solos LVd3, RQo1 e $\mathrm{LVd} 4$, respectivamente) com volume $\left(\mathrm{m}^{3}\right)$ de árvore individual com casca $(v)$, volume de árvore individual sem casca $\left(\mathrm{v}_{\mathrm{sc}}\right)$, volume por hectare com casca $(\mathrm{V})$, volume por hectare sem casca $\left(\mathrm{V}_{\mathrm{sc}}\right)$, diâmetro à altura do peito (DAP) e altura total (h). As unidades amostrais circulares, medindo $314 \mathrm{~m}^{2}$ cada, foram distribuídas de forma sistemática na área de efetivo plantio. Foi medido o DAP de todas as árvores de cada parcela (36) bem como a h das 15 primeiras árvores de cada amostra, mais as árvores dominadas, para possibilitar o ajuste de uma equação de regressão, a fim de estimar a altura das demais árvores. Para realizar as estimativas de volume comercial, foi utilizada a equação matemática ajustada a partir de cubagens de fustes de eucalipto na região, expressa por: 
$\mathrm{VC}=\mathrm{b}_{0}+\mathrm{b}+{ }_{1} \times \mathrm{DAP}+\mathrm{b}_{2} \times \mathrm{DAP}^{2}+\mathrm{b}_{3} \times($ DAP $\times \mathrm{h})+$ $b_{4} \times\left(D A P^{2} x h\right)+b_{5} x h$

em que: $\mathrm{VC}=$ Volume comercial; $\mathrm{DAP}=$ Diâmetro à altura do peito; $\mathrm{h}=$ altura total.

No mesmo período de realização do inventário, amostras de solo foram obtidas das camadas de $0-20$ e $20-40 \mathrm{~cm}$ de profundidade e os principais atributos foram analisados de acordo com TEDESCO et al. (1995): teor de argila, matéria orgânica, $\mathrm{pH}-\mathrm{H}_{2} \mathrm{O}$, pH-SMP, Al trocável, acidez titulável a pH 7,0, CTC efetiva, CTC pH 7,0, P e K disponíveis (Mehlich I), $\mathrm{Ca}$ e $\mathrm{Mg}$ trocáveis, saturação por bases e por $\mathrm{Al}$, soma de bases e teores de S, B, Cu e Zn. Em cada sítio, foi coletado com pá de corte um ponto de amostragem para cada oito hectares de plantio, distribuídos sistematicamente no mesmo local.

A determinação do nível crítico dos atributos químicos mais limitantes foi realizada através de adaptação do procedimento descrito por CANTARUTTI et al. (2007). Sobre o gráfico que relaciona o rendimento relativo de um parâmetro de crescimento/produção da planta (eixo Y) e um parâmetro químico de solo (eixo $\mathrm{X}$ ), fixou-se o rendimento relativo em $80 \%$ e determinou-se o nível crítico do parâmetro químico no valor de eixo $\mathrm{X}$ que proporcionasse a menor soma de pontos dos quadrantes II e IV (para os casos em que baixo valor do atributo implique em redução do crescimento das plantas) ou I e III (para os casos em que o alto valor do atributo implique em redução do crescimento das plantas). O valor de $80 \%$ do rendimento relativo foi escolhido arbitrariamente, uma vez que este normalmente varia entre 80 e $90 \%$, conforme a relação entre o preço do insumo e o preço do produto (CANTARUTTI et al., 2007).

A análise estatística dos dados foi realizada no programa estatístico SAS. As relações entre as variáveis de crescimento e os atributos do solo nas profundidades de $0-20$ e $20-40 \mathrm{~cm}$ foram avaliadas através da significância do coeficiente de correlação de Pearson $(\mathrm{P}<0,05)$.

\section{RESULTADOS E DISCUSSÃO}

A maior produção em volume por ha $(\mathrm{V})$ no segundo ano de plantio foi alcançada no solo $\mathrm{LVd} 3$ com $35,68 \mathrm{~m}^{3}$, enquanto, no solo RQo1, a média foi de apenas $22,20 \mathrm{~m}^{3}$, o que equivale a uma redução de cerca de $40 \%$, com alguns valores aproximadamente $50 \%$ menores do que os tetos obtidos entre os locais avaliados neste estudo (Tabela 1). Essa tendência nos resultados se repetiu para as demais variáveis de crescimento avaliadas e sugere que a adequação do manejo nutricional para o solo RQo1 poderá elevar a sua produtividade para valores mais próximos aos obtidos em solo LVd3 e LVd4, uma vez que

Tabela 1 - Variáveis dendrométricas e seus respectivos rendimentos relativos em povoamentos de Eucalyptus saligna aos 28 meses de idade.

\begin{tabular}{|c|c|c|c|c|c|c|c|}
\hline Solo $^{1}$ & $\mathrm{v}^{2}\left(\mathrm{~m}^{3}\right)$ & $\mathrm{V}_{\mathrm{RR}}^{3}(\%)$ & $\operatorname{DAP}^{4}(\mathrm{~cm})$ & $\operatorname{DAP}_{\mathrm{RR}}^{5}(\%)$ & $\mathrm{V}^{6}\left(\mathrm{~m}^{3} \mathrm{ha}^{-1}\right)$ & $\mathrm{V}_{\mathrm{sc}}^{7}\left(\mathrm{~m}^{3} \mathrm{ha}^{-1}\right)$ & $\mathrm{h}^{8}(\mathrm{~m})$ \\
\hline $\mathrm{LVd} 3$ & 0,031 & 83,26 & 11,10 & 84,41 & 25,50 & 22,60 & 12,20 \\
\hline LVd3 & 0,021 & 56,36 & 11,00 & 83,65 & 19,30 & 17,20 & 12,30 \\
\hline $\mathrm{LVd} 3$ & 0,038 & 100,00 & 13,15 & 100,00 & 34,85 & 30,08 & 13,80 \\
\hline LVd3 & 0,033 & 87,43 & 11,55 & 87,83 & 35,68 & 31,50 & 13,50 \\
\hline LVd3 & 0,033 & 88,51 & 11,70 & 88,97 & 34,55 & 30,35 & 13,15 \\
\hline RQo1 & 0,021 & 56,24 & 9,90 & 75,29 & 23,65 & 21,20 & 11,20 \\
\hline RQo1 & 0,017 & 46,39 & 9,00 & 68,44 & 17,83 & 15,80 & 10,35 \\
\hline RQo1 & 0,022 & 58,93 & 9,40 & 71,48 & 22,65 & 20,13 & 11,40 \\
\hline RQo1 & 0,027 & 72,01 & 10,50 & 79,85 & 27,68 & 24,30 & 11,75 \\
\hline RQo1 & 0,019 & 50,05 & 9,40 & 71,48 & 20,73 & 19,10 & 11,15 \\
\hline RQo1 & 0,019 & 49,96 & 9,30 & 70,72 & 19,20 & 17,28 & 10,95 \\
\hline LVd4 & 0,031 & 82,87 & 11,50 & 87,45 & 29,35 & 25,88 & 12,90 \\
\hline LVd4 & 0,027 & 71,98 & 10,70 & 81,37 & 28,10 & 25,03 & 12,75 \\
\hline LVd4 & 0,033 & 87,73 & 11,80 & 89,73 & 35,80 & 30,30 & 12,50 \\
\hline LVd4 & 0,034 & 89,58 & 11,85 & 90,11 & 35,48 & 31,00 & 12,70 \\
\hline LVd4 & 0,033 & 86,93 & 11,70 & 88,97 & 36,00 & 31,68 & 13,00 \\
\hline LVd4 & 0,037 & 98,58 & 13,00 & 98,86 & 39,08 & 34,00 & 13,10 \\
\hline LVd4 & 0,029 & 77,64 & 10,90 & 82,89 & 30,78 & 27,20 & 12,50 \\
\hline
\end{tabular}

${ }^{1}$ LVD3: Latossolo Vermelho Distrófico; LVD4: Latossolo Vermelho Distrófico típico; RQo1: Neossolo Quartzarênico Órtico típico; ${ }^{2}$ volume individual com casca; ${ }^{3}$ rendimento relativo do volume individual com casca; ${ }^{4}$ diâmetro à altura do peito; ${ }^{5}$ rendimento relativo do diâmetro à altura do peito; ${ }^{6}$ volume com casca por hectare; ${ }^{7}$ volume sem casca por hectare; ${ }^{8}$ altura total. 
estes locais se localizam relativamente próximos, o material genético utilizado foi o mesmo e as práticas de manejo empregadas foram semelhantes (apesar das diferenças intrínsecas entre os solos).

Os atributos químicos dos solos, em geral (Tabela 2), podem ser classificados, de acordo com os teores de referência para a interpretação da fertilidade do solo no RS e SC (COMISSÃO, 2004), em: MO baixo, $\mathrm{pH}-\mathrm{H}_{2} \mathrm{O}$ - muito baixo; Saturação por bases muito baixo; Saturação por Alumínio - muito alto; $\mathrm{P}$ Mehlich-1 - baixo; K - muito baixo; Mg - baixo;
$\mathrm{Ca}$ - baixo; $\mathrm{B}$ - alto; $\mathrm{Cu}$ - alto; $\mathrm{Zn}$ - alto. Destaca-se que o solo RQo1 apresentou os piores atributos em relação à acidez, uma vez que, nesse solo, encontrouse a mais baixa saturação por bases $(2,33 \%)$, a mais alta saturação por $\mathrm{Al}(92,17 \%)$ e o menor teor de $\operatorname{Mg}\left(0,01 \mathrm{cmol}_{c} \mathrm{dm}^{-3}\right)$. Esses valores são considerados prejudiciais até mesmo para plantas tolerantes a solos ácidos e à toxidez por Al como o eucalipto (RIBEIRO et al., 1999; COMISSÃO, 2004; EMBRAPA, 2012) e estão relacionados à elevada lixiviação e ao material de origem dos solos avaliados. A textura arenosa, os

Tabela 2 - Atributos químicos de solos $(0-20 \mathrm{~cm}$ e $20-40 \mathrm{~cm})$ sob povoamento de Eucalyptus saligna aos 28 meses de idade em três solos da região do Pampa Gaúcho.

\begin{tabular}{|c|c|c|c|c|c|c|c|c|c|c|c|c|c|c|c|}
\hline Solo & Prof. & $\begin{array}{l}\text { MO } \\
\%\end{array}$ & $\mathrm{pH}-\mathrm{H}_{2} \mathrm{O}$ & $\mathrm{pH}-\mathrm{MP}$ & ------. & $\begin{array}{l}\mathrm{H}+\mathrm{AL} \\
\end{array}$ & $\begin{array}{l}\mathrm{CTC}_{\mathrm{e}} \\
\mathrm{l}_{\mathrm{c}} \mathrm{dm}^{-3}--\end{array}$ & CTC7 & $\begin{array}{c}\text { Argila } \\
\quad \%\end{array}$ & $\begin{array}{c}\mathrm{P} \\
---\mathrm{mg} \mathrm{d} n\end{array}$ & $n^{-3}---$ & $\begin{array}{c}\mathrm{Ca} \\
----\mathrm{cmc}\end{array}$ & $\begin{array}{c}\mathrm{Mg} \\
\mathrm{Am}^{-3}----\end{array}$ & \multirow{2}{*}{$\begin{array}{c}\mathrm{m} \\
\% \\
28,93\end{array}$} & \multirow{2}{*}{$\begin{array}{c}\mathrm{V} \\
\% \\
24,67\end{array}$} \\
\hline $\mathrm{LVd} 3$ & $0-20$ & 1,0 & 4,8 & 5,8 & 0,73 & 5,49 & 2,53 & 7,28 & 15,00 & 6,72 & 92 & 0,71 & 0,85 & & \\
\hline $\mathrm{LVd} 3$ & $20-40$ & 1,0 & 4,9 & 5,6 & 1,09 & 6,90 & 3,23 & 9,03 & 11,00 & 13,27 & 84 & 1,17 & 0,75 & 33,99 & 23,57 \\
\hline LVd3 & $0-20$ & 1,0 & 4,5 & 5,5 & 1,83 & 7,74 & 2,97 & 8,88 & 15,44 & 8,57 & 35 & 0,39 & 0,65 & 61,28 & 12,82 \\
\hline LVd3 & $20-40$ & 0,9 & 4,6 & 5,5 & 1,58 & 7,74 & 2,59 & 8,74 & 13,44 & 2,86 & 21 & 0,57 & 0,38 & 74,13 & 11,45 \\
\hline $\mathrm{LVd} 3$ & $0-20$ & 0,7 & 4,5 & 5,8 & 1,71 & 5,50 & 2,30 & 6,08 & 17,44 & 2,18 & 13 & 0,21 & 0,36 & 74,13 & 9,79 \\
\hline $\mathrm{LVd} 3$ & $20-40$ & 0,7 & 4,6 & 5,7 & 1,71 & 6,15 & 2,47 & 6,92 & 7,44 & 7,39 & 12 & 0,37 & 0,40 & 69,13 & 11,01 \\
\hline LVd3 & $0-20$ & 0,8 & 4,6 & 5,8 & 1,22 & 5,50 & 1,80 & 6,06 & 5,44 & 3,19 & 29 & 0,10 & 0,40 & 67,89 & 9,50 \\
\hline LVd3 & $20-40$ & 0,7 & 4,5 & 5,7 & 1,58 & 6,15 & 2,07 & 6,64 & 7,44 & 4,37 & 21 & 0,13 & 0,30 & 76,55 & 7,31 \\
\hline LVd3 & $0-20$ & 1,0 & 4,7 & 5,6 & 1,58 & 6,90 & 2,83 & 8,15 & 9,44 & 2,69 & 21 & 0,50 & 0,70 & 55,90 & 15,33 \\
\hline $\mathrm{LVd} 3$ & $20-40$ & 1,1 & 4,6 & 5,3 & 1,95 & 9,79 & 3,24 & 11,03 & 7,44 & 3,19 & 18 & 0,77 & 0,47 & 60,23 & 11,67 \\
\hline RQo1 & $0-20$ & 0,8 & 4,3 & 5,9 & 1,95 & 4,89 & 2,24 & 5,18 & 15,44 & 5,71 & 23 & 0,01 & 0,18 & 87,14 & 5,56 \\
\hline RQo1 & $20-40$ & 0,7 & 4,3 & 5,9 & 1,34 & 4,89 & 1,54 & 5,09 & 15,44 & 4,03 & 21 & 0,01 & 0,10 & 86,81 & 4,00 \\
\hline RQo1 & $0-20$ & 0,7 & 4,4 & 6,0 & 1,22 & 4,36 & 1,43 & 4,58 & 13,44 & 6,55 & 24 & 0,01 & 0,10 & 84,98 & 4,71 \\
\hline RQo1 & $20-40$ & 0,6 & 4,3 & 6,0 & 1,22 & 4,36 & 1,36 & 4,50 & 15,44 & 4,20 & 17 & 0,01 & 0,05 & 89,46 & 3,19 \\
\hline RQo1 & $0-20$ & 0,8 & 4,5 & 6,0 & 0,85 & 4,36 & 1,24 & 4,75 & 11,44 & 3,53 & 22 & 0,01 & 0,28 & 68,83 & 8,14 \\
\hline RQo1 & $20-40$ & 0,7 & 4,4 & 5,9 & 1,10 & 4,89 & 1,30 & 5,09 & 11,44 & 3,53 & 14 & 0,01 & 0,11 & 84,59 & 3,92 \\
\hline RQo1 & $0-20$ & 0,6 & 4,3 & 6,2 & 0,97 & 3,47 & 1,07 & 3,56 & 7,44 & 7,56 & 8 & 0,01 & 0,01 & 91,51 & 2,54 \\
\hline RQo1 & $20-40$ & 0,5 & 4,2 & 6,2 & 0,97 & 3,47 & 1,06 & 3,55 & 5,44 & 5,54 & 6 & 0,01 & 0,01 & 91,95 & 2,40 \\
\hline RQo1 & $0-20$ & 0,5 & 4,4 & 6,2 & 0,97 & 3,47 & 1,06 & 3,55 & 7,44 & 6,55 & 5 & 0,01 & 0,01 & 92,17 & 2,33 \\
\hline RQo1 & $20-40$ & 0,4 & 4,3 & 6,3 & 0,97 & 3,09 & 1,06 & 3,17 & 9,44 & 5,71 & 5 & 0,01 & 0,01 & 92,17 & 2,61 \\
\hline RQo1 & $0-20$ & 0,6 & 4,3 & 6,2 & 0,85 & 3,47 & 0,96 & 3,58 & 9,44 & 3,53 & 11 & 0,01 & 0,01 & 88,56 & 3,08 \\
\hline RQo1 & $20-40$ & 0,6 & 4,2 & 6,1 & 0,97 & 3,89 & 1,07 & 3,98 & 9,44 & 3,02 & 11 & 0,01 & 0,01 & 91,11 & 2,39 \\
\hline LVd4 & $0-20$ & 0,8 & 4,4 & 5,9 & 0,97 & 4,89 & 1,44 & 5,36 & 15,44 & 3,02 & 28 & 0,01 & 0,35 & 67,63 & 8,71 \\
\hline LVd4 & $20-40$ & 0,7 & 4,4 & 5,9 & 1,34 & 4,89 & 1,68 & 5,24 & 15,44 & 2,69 & 20 & 0,01 & 0,24 & 79,57 & 6,57 \\
\hline LVd4 & $0-20$ & 0,9 & 4,6 & 5,8 & 1,22 & 5,49 & 2,08 & 6,35 & 17,44 & 3,36 & 72 & 0,17 & 0,51 & 58,59 & 13,57 \\
\hline LVd4 & $20-40$ & 0,8 & 4,5 & 5,6 & 1,58 & 6,90 & 2,10 & 7,42 & 17,44 & 2,69 & 48 & 0,13 & 0,27 & 75,36 & 6,98 \\
\hline LVd4 & $0-20$ & 0,7 & 4,5 & 6,0 & 0,97 & 4,36 & 1,65 & 5,04 & 15,44 & 5,04 & 35 & 0,11 & 0,48 & 59,07 & 13,41 \\
\hline $\mathrm{LVd} 4$ & $20-40$ & 0,7 & 4,4 & 5,8 & 0,61 & 5,49 & 1,06 & 5,94 & 17,44 & 3,36 & 24 & 0,10 & 0,30 & 57,22 & 7,66 \\
\hline LVd4 & $0-20$ & 0,8 & 4,5 & 6,0 & 0,97 & 4,36 & 1,46 & 4,84 & 13,44 & 2,86 & 27 & 0,01 & 0,38 & 66,82 & 9,99 \\
\hline LVd4 & $20-40$ & 0,6 & 4,5 & 5,9 & 1,22 & 4,89 & 1,51 & 5,18 & 15,44 & 1,85 & 23 & 0,01 & 0,18 & 80,73 & 5,61 \\
\hline LVd4 & $0-20$ & 0,9 & 4,5 & 5,9 & 0,97 & 4,89 & 2,23 & 6,14 & 13,44 & 2,69 & 47 & 0,42 & 0,72 & 43,75 & 20,40 \\
\hline LVd4 & $20-40$ & 0,9 & 4,6 & 5,9 & 0,85 & 4,89 & 2,64 & 6,68 & 17,44 & 2,35 & 36 & 1,01 & 0,68 & 32,29 & 26,77 \\
\hline LVd4 & $0-20$ & 0,8 & 4,3 & 5,9 & 0,97 & 4,89 & 1,45 & 5,37 & 9,44 & 4,54 & 42 & 0,01 & 0,32 & 67,22 & 8,86 \\
\hline LVd4 & $20-40$ & 0,7 & 4,3 & 5,9 & 1,34 & 4,89 & 2,53 & 6,08 & 11,44 & 3,53 & 41 & 0,01 & 1,03 & 53,08 & 19,50 \\
\hline LVd4 & $0-20$ & 0,7 & 4,4 & 6,1 & 0,85 & 3,89 & 1,07 & 4,10 & 7,44 & 4,03 & 27 & 0,01 & 0,10 & 79,79 & 5,26 \\
\hline LVd4 & $20-40$ & 0,7 & 4,3 & 6,1 & 0,98 & 3,89 & 1,12 & 4,03 & 7,44 & 3,02 & 25 & 0,01 & 0,10 & 87,45 & 3,48 \\
\hline
\end{tabular}


baixos teores de matéria orgânica e a baixa atividade da fração argila favorecem uma elevada perda de cátions de natureza básica por lixiviação, os quais já são naturalmente baixos nos arenitos e siltitos que predominam como material de origem na região (STRECK et al., 2008). Com a lixiviação destes, acumulam-se os cátions de natureza ácida $\left(\mathrm{Al}^{+3} \mathrm{e} \mathrm{o}\right.$ $\mathrm{H}^{+}$) no solo (ELTZ et al., 2005).

Os atributos químicos de solo que apresentaram maior correlação com as variáveis de crescimento de planta foram o teor de $\mathrm{Mg}$ trocável, a saturação por $\mathrm{Al}(\mathrm{m})$ e a saturação por bases (V) (Tabela 3), evidenciando que estes foram os principais limitantes químicos dos locais avaliados. Portanto, os resultados sugerem que, ao se adequar os teores destas variáveis às exigências da cultura, os ganhos em crescimento poderiam ser elevados.
Verificou-se ainda que o maior número de correlações significativas $(\mathrm{P}<0,05)$ entre parâmetros químicos de solo e dados de inventário foram apresentadas na camada de $0,20-0,40 \mathrm{~m}$, sendo as mais expressivas as relações do $\mathrm{Mg}$ com o DAP, $\mathrm{v}$ e $\mathrm{v}_{\mathrm{sc}}(\mathrm{P}<0,01)$. Logo, em solos arenosos e lixiviados como o do estudo, a consideração de atributos químicos das camadas subsuperficiais de solo parece ser essencial para o sucesso do sistema de recomendação de adubação e calagem de novos plantios de eucalipto da região.

Os níveis críticos calculados de saturação por $\mathrm{Al}$ para obtenção do rendimento relativo de $80 \%$ para o diâmetro e volume por árvore foram de $75 \mathrm{e}$ $83 \%$, respectivamente (média de 79\%; Figura 1A e 1B). Tais valores são bem maiores que $10 \%$, considerado crítico para a maioria das culturas (COMISSÃO, 2004), e de $45 \%$, considerado crítico para o eucalipto

Tabela 3 - Correlação de Pearson entre variáveis dendrométricas e atributos químicos do solo na profundidade de 0-20 cm e $20-40 \mathrm{~cm}$ sob povoamento de Eucalyptus saligna aos 28 meses de idade, em três solos da região do Pampa Gaúcho, demonstrando o coeficiente de correlação (R) e a sua significância $(\mathrm{P} ; \mathrm{n}=18)$.

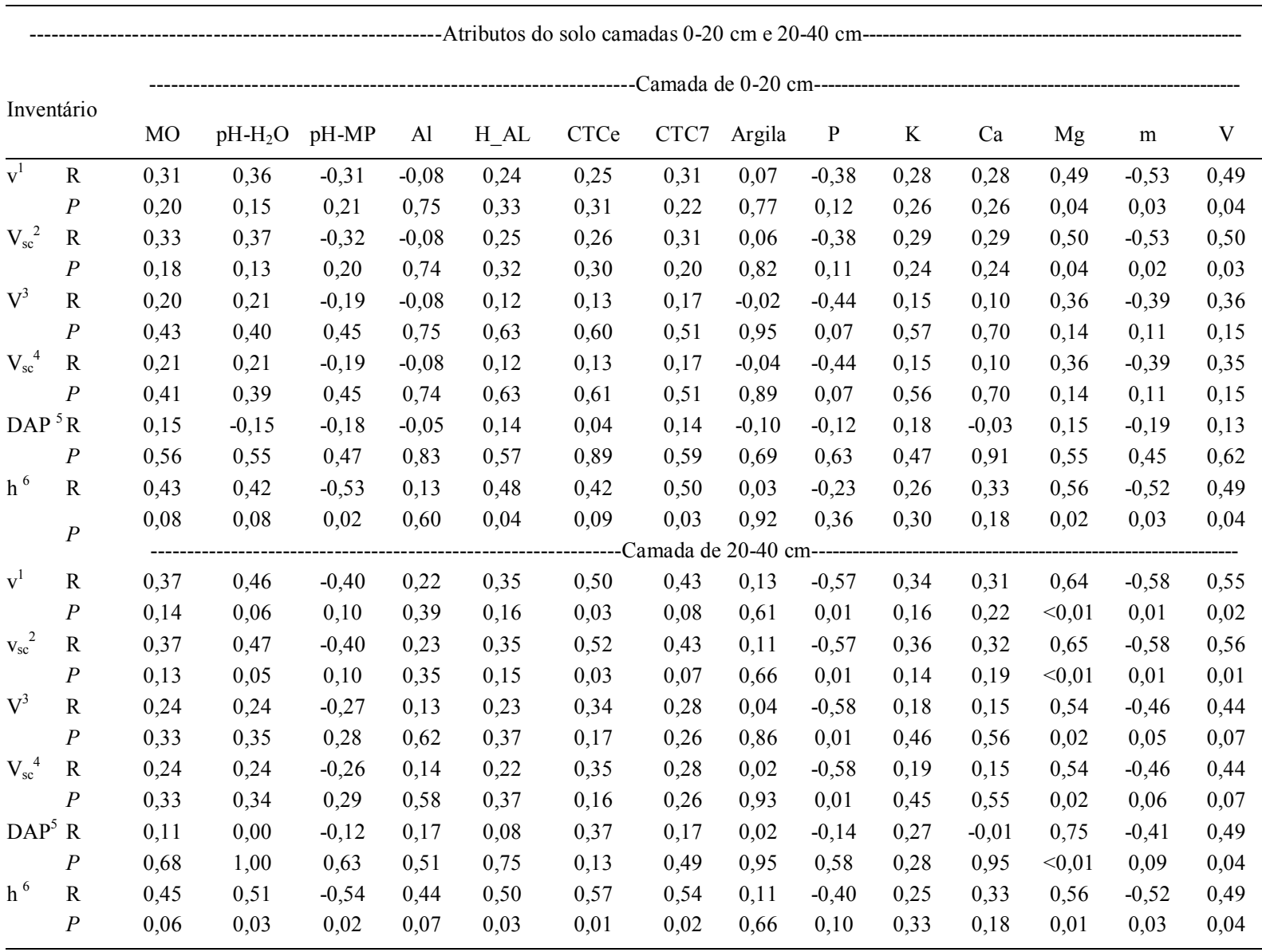

${ }^{1}$ volume individual com casca; ${ }^{2}$ volume individual sem casca; ${ }^{3}$ volume por hectare com casca; ${ }^{4}$ volume por hectare sem casca; ${ }^{5}$ diâmetro à altura do neito: ${ }^{6}$ altura. 


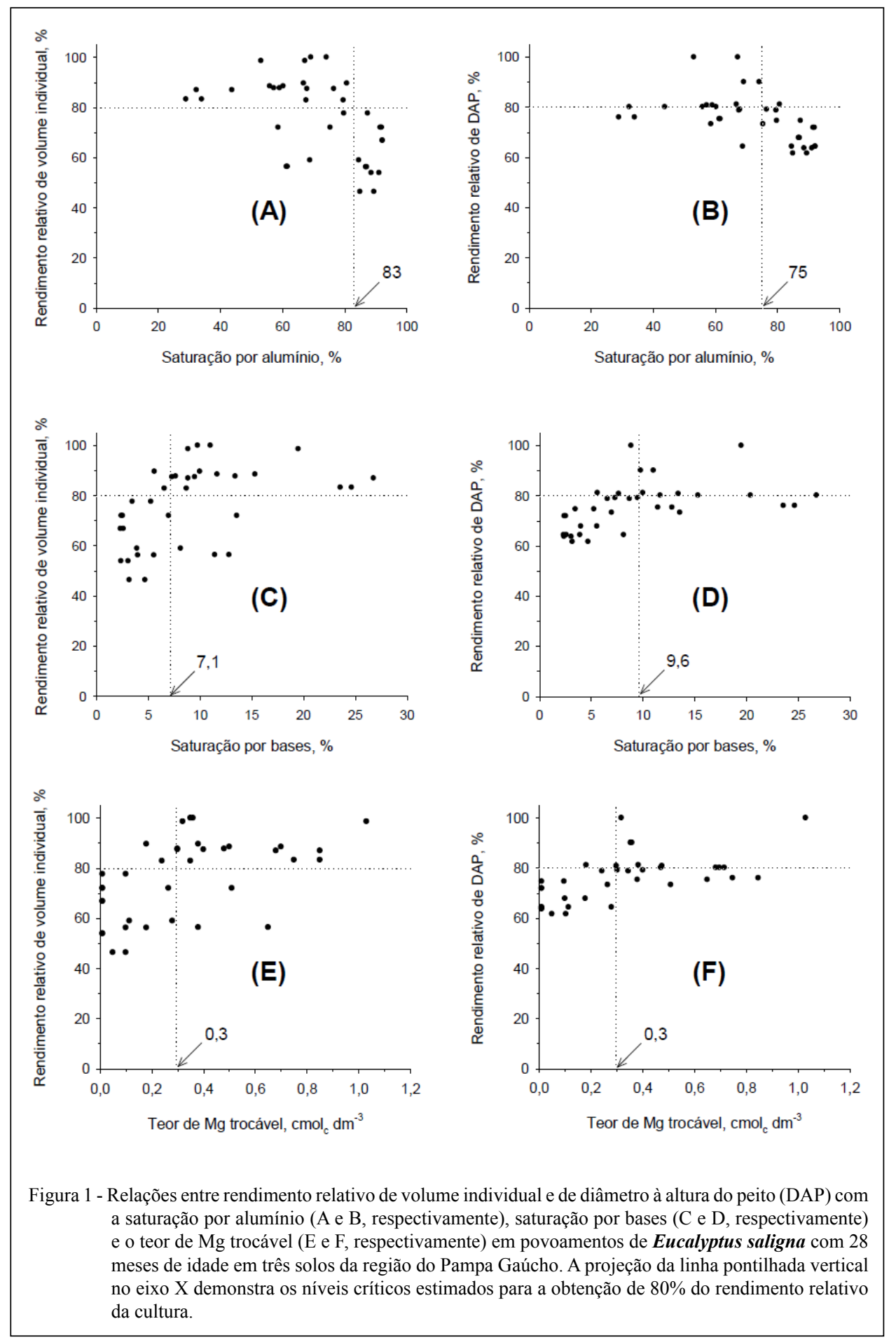

(RIBEIRO et al., 1999), no qual, acima deste valor, aumenta a probabilidade de decréscimo de produção pela toxidez por Al. Estes resultados corroboram com o fato de que o eucalipto é mais tolerante ao Al que a maioria das plantas. Os mecanismos de tolerância ao Al são vários, podendo ser fisiológicos (SILVA et al.,
2004; POSCHENRIEDER et al., 2008) e/ou indiretos, pela complexação do Al pela fração orgânica presente (VIEIRA et al., 2008). Como o estudo foi realizado com plantas ainda jovens, é provável que o futuro acúmulo de serrapilheira e C lábil nos solos desses locais amenizem o efeito restritivo causado pela toxidez por $\mathrm{Al}$, porém 
estudos devem ser realizados para evidenciar esse efeito no fim de ciclo destas árvores.

Os níveis críticos calculados de saturação por bases para o rendimento relativo de $80 \%$ no diâmetro e volume por árvore foram de $9,6 \%$ e $7,1 \%$, respectivamente (media de $8,3 \%$; Figura $1 \mathrm{C}$ e 1D). Esses valores são inferiores aos $30-50 \%$ recomendados para o eucalipto (RIBEIRO et al., 1999; EMBRAPA, 2012) e ao valor mínimo de $65 \%$ considerado ideal para a maioria das culturas do Sul do Brasil (COMISSÃO, 2004). Tais diferenças evidenciam que a interpretação dos parâmetros químicos para a cultura do eucalipto não pode ser realizada com os mesmos critérios utilizados para a média das culturas anuais e perenes.

O nível crítico do teor de $\mathrm{Mg}$ trocável $\left(\mathrm{cmol}_{\mathrm{c}} \mathrm{dm}^{-3}\right)$, calculado para obter $80 \%$ do rendimento relativo para o diâmetro e volume por árvore, foi de $0,3 \mathrm{cmol}_{\mathrm{c}} \mathrm{dm}^{-3}$ para ambas variáveis (Figura $1 \mathrm{E}$ e $1 \mathrm{~F}$, respectivamente). Logo, com uma pequena adição de calcário dolomítico, a deficiência do $\mathrm{Mg}$ para a cultura poderia ser corrigida, favorecendo conjuntamente a melhoria na saturação por bases epor Al. Nesse caso, provavelmente, a aplicação de calcário objetivando a elevação do $\mathrm{pH}$ a 5,5 ou a elevação da saturação por bases para $65 \%$ implique gasto excessivo desse insumo e menor retorno econômico, devido à baixa resposta da cultura à aplicação. Para elevar o pH- $\mathrm{H}_{2} \mathrm{O}$ do solo a 5,5 pela recomendação através do método SMP, utilizando um calcário dolomítico disponível na região ( $\mathrm{MgO}$ 14,75\% com PRNT 63,79\%), seriam necessárias aplicações de 4,39, 3,14 e 1,57 $\mathrm{Mg} \mathrm{ha}^{-1}$ para os solos LVD3, LVD4 e RQo1, respectivamente. Entretanto, utilizando o mesmo calcário para elevar o teor de $\mathrm{Mg}$ do solo de $0,01 \mathrm{cmol} \mathrm{dm}^{-3}$ para $0,30 \mathrm{cmol}$ $\mathrm{dm}^{-3}$ (teor crítico calculado) para a camada de $0-20 \mathrm{~cm}$ de profundidade, a aplicação seria necessária apenas no solo RQo1, com uma recomendação de $0,29 \mathrm{Mg}$ $\mathrm{ha}^{-1}$. Assim, os custos com aquisição e aplicação desse insumo seriam consideravelmente reduzidos.

Ao observar os resultados do presente estudo, é importante considerar que foram obtidos de plantios de apenas dois anos de idade e que o rendimento relativo considerado para determinação dos níveis críticos foi de $80 \%$. Em adição, nenhuma das 18 unidades amostrais avaliadas apresentou atributos de acidez próximos do que seria ideal para a maioria das culturas, o que talvez pudesse reduzir os valores de rendimento relativo dos demais sítios avaliados, alterando o valor dos limites críticos calculados. Porém, os resultados reforçam a necessidade da determinação de níveis críticos específicos para as plantações com eucalipto na região, em especial nos solos arenosos, onde os níveis críticos empregados atualmente podem superestimar as dosagens recomendadas para calagem e fertilização.

\section{CONCLUSÃO}

A saturação por Al, a saturação por bases e o teor de $\mathrm{Mg}$ trocável foram os atributos químicos do solo que mais limitaram o crescimento das plantas. O nível crítico médio estimado para promover $80 \%$ de rendimento relativo das plantas foi de $79 \%$ para a saturação por $\mathrm{Al}, 8 \%$ para a saturação por bases $(\mathrm{V} \%)$ e $0,3 \mathrm{cmol}_{\mathrm{c}} \mathrm{dm}^{-3}$ para o teor de $\mathrm{Mg}$ trocável. Os atributos químicos de solo da camada subsuperficial (20-40cm de profundidade) apresentaram maior relação com os parâmetros de crescimento das plantas do que a camada superficial.

\section{AGRADECIMENTOS}

Os autores agradecem à empresa Stora Enso Florestal RS pela disponibilização dos dados utilizados no estudo.

\section{REFERENCIAS}

ABRAF. Anuário Estatístico 2013 - ano base 2012. Online. Disponível em: <http://www.abraflor.org.br/estatisticas/ ABRAF13/ABRAF13-BR.pdf>. Acesso em: 12 maio 2014.

BARROS, N.F. et al. Recomendações de fertilizantes minerais em plantios de eucalipto. In: GONÇALVES, J.L.M.; BENEDETTI, V. Nutrição e fertilização florestal. Piracicaba: IPEF, 2004. p.269-286.

BARROS, N.F.; NOVAIS, R.F. Fertilização e correção do solo para o plantio de eucalipto. In: BARROS, N.F; NOVAIS, R.F. Relação solo eucalipto. Viçosa: Folha de Viçosa, 1990. p.127-181.

CANTARUTTI, R.B. Avaliação da fertilidade do solo e recomendação de fertilizantes. In: NOVAIS, et al. Fertilidade do solo. Viçosa: UFV, 2007. p.769-850.

COMISSÃO DE QUÍMICA E FERTILIDADE DO SOLO - RS/ SC. Manual de adubação e calagem para os estados do Rio Grande do Sul e de Santa Catarina. Porto Alegre: SBCS/NRS, 2004. 400p.

ELTZ, F.L.F.; ROVEDDER, A.P.M. Revegetação e temperatura do solo em áreas degradadas no sudoeste do Rio Grande do Sul. Revista Brasileira de Agrociência, v.11, n.2, p.193-200, jun 2005. Disponível em: <http://www.ufpel.tche.br/faem/agrociencia/ v11n2/artigo10.pdf>. Acesso em: 22 jun. 2012.

EMPRESA BRASILEIRA DE PESQUISA AGROPECUÁRIA. Centro Nacional de Pesquisa de Solos. Sistema Brasileiro de Classificação de Solos. Rio de Janeiro, 2006. 306p.

EMPRESA BRASILEIRA DE PESQUISA AGROPECUÁRIA. Online. Disponível em: <http://sistemasdeproducao.cnptia. embrapa.br/FontesHTML/Eucalipto/CultivodoEucalipto/05_05_ recomendacao_de_calagem.htm $>$. Acesso em: 17 jun. 2012. 
GONÇALVES, J.L.M.; BENEDETTI, V. Nutrição e fertilização florestal. Piracicaba: IPEF, 2004. 427p.

GONÇALVES, J.L.M. Principais solos usados para plantações florestais. In: GONÇALVES, J.L.M.; STAPE, J.L. Conservação e cultivo de solos para plantações florestais. Piracicaba: IPEF, 2002. 498p.

POSCHENRIEDER, C. et al. A glance into aluminum toxicity and resistance in plants. Science of the total environment, v.400, n.1-3, p. 356-368, ago. 2008. Disponível em: $<$ http://www.scopus. com/record/display.url?eid=2-s2.0-54349084259\&origin=inward $\&$ txGid=jaJ98w8cP0jXz zJx1oK-Wo\%3a2>. Acesso em: 26 jun. 2012. doi: 10.1016/j.scitotenv.2008.06.003.

RIBEIRO, A.C. et al. Recomendação para o uso de corretivos e fertilizantes em Minas Gerais - $5^{\mathbf{a}}$ aproximação. Viçosa, MG: Universidade Federal de Viçosa, 1999. 359p.

SILVA, I.R. et al. Responses of eucalypt species to aluminum: the possible involvement of low molecular weight organic acids in the Al tolerance mechanism. Tree Physiology, v.24, p.1267-1277, nov. 2004. Disponível em: <http://treephys.oxfordjournals.org/ content/24/11/1267.full.pdf + html $>$. Acesso em 25 jun.2012. doi: $10.1093 /$ treephys/24.11.1267.
STRECK, E.V. et al. Solos do Rio Grande do Sul. Porto Alegre: UFRGS, EMATER/RS, 2002. 107p.

TAHARA, K. et al. Role of aluminum-binding ligands in aluminum resistance of Eucalyptus camaldulensis and Melaleuca cajuputi. Plant and Soil, v.302, n.1-2, p.175-187, jan. 2008. Disponível em: <http://rd.springer.com/article/10.1007/s11104-007-9464-5>. Acesso em: 23 jun. 2012. doi: 10.1007/s11104-007-9464-5.

TEDESCO, M.J. et al. Análise de solo, plantas e outros materiais. 2.ed. Porto Alegre: Departamento de Solos: UFRGS, 1995. 174p.

VALE, F.R. et al. Crescimento radicular de espécies florestais em solo ácido. Pesquisa Agropecuária Brasileira, v.31, n.9, p.609616, set. 1996. Disponível em: <http://webnotes.sct.embrapa.br/ pab/pab.nsf/ecd4ca3ff88efcfa032564cd004ea083/b499a382dcf0e 573032567ba004b1edd/\$FILE/pab96_02_set.pdf>. Acesso em: 27 jun. 2012.

VIEIRA, F.C.B. et al. Organic amendment effect on the transformation and fractionation of aluminum in acidic sandy soil. Communications in soil science and plant analysis, v.39, p.2678-2694, nov., 2008. Disponível em: <http://www.tandfonline. com/doi/abs/10.1080/00103620802358813>. Acesso em: 23 jun. 2012. doi: $10.1080 / 00103620802358813$. 